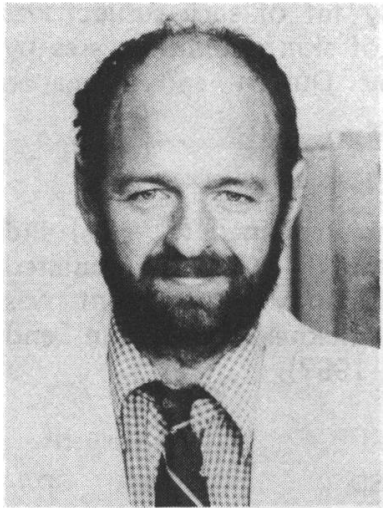

R. J. Maughan

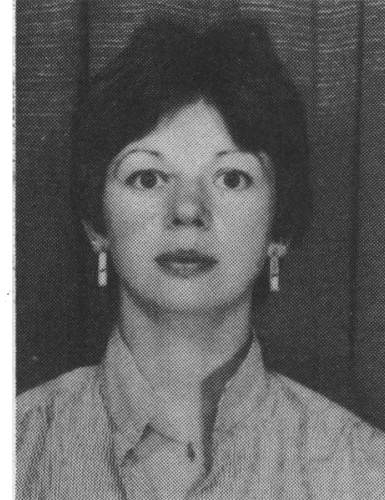

Jennifer Watson

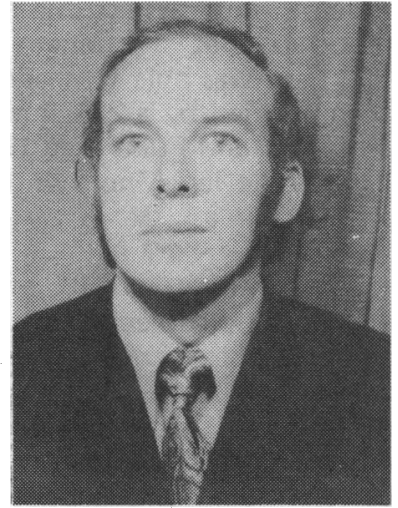

J. Weir

\title{
MUSCLE STRENGTH AND CROSS-SECTIONAL AREA IN MAN: A COMPARISON OF STRENGTH-TRAINED AND UNTRAINED SUBJECTS
}

\author{
R. J. MAUGHAN, Jennifer S. WATSON* and J. WEIR* \\ Institute of Environmental and Offshore Medicine and *Department of Radiology, \\ University Medical School, Foresterhill, Aberdeen, AB9 $2 Z D$
} \begin{abstract}
increased angle of pennation in the larger muscles.
Key words: Skeletal muscle, Strength, Training.

\section{INTRODUCTION}

In normal healthy subjects, it has been established that the maximum voluntary isometric force which can be produced by human skeletal muscle is proportional to the muscle cross-sectional area (Ikai and Fukunaga, 1968; Maughan et al, 1983). In these studies, however, considerable variability in the ratio of strength to cross-
\end{abstract}

ABSTRACT

This study has examined muscle strength and cross-sectional area in a group of $\mathbf{3 5}$ healthy untrained male subjects an 8 subjects who had been engaged in a strenuous weight-training programme. The maximum voluntary knee extension force which could be produced by the untrained subjects was $742 \pm 100 \mathrm{~N}$ (mean \pm SD). The trained subjects could produce a significantly $(p<0.001)$ greater force $(992 \pm 162 \mathrm{~N})$. Cross-sectional area of the knee-extensor muscle group was $81.6 \pm 11.8 \mathrm{~cm}^{2}$ in the untrained subjects and $104.1 \pm 12.3 \mathrm{~cm}^{2}$ in the trained subjects $(\mathrm{p}<0.001)$. In the untrained subjects, a significant correlation existed between strength and muscle cross-sectional area $(r=0.56, p<0.001)$. In the same group of subjects, there was a significant inverse relationship between muscle cross-sectional area and the ratio of strength to cross-sectional area $(r=-0.55, p<0.001)$. The mean ratio of strength to cross-sectional area was $9.20 \pm 1.29$ for the untrained group whereas for the trained group this ratio was $9.53 \pm 1.01$. It is suggested that the inverse relationship between strength per unit cross-sectional area and cross-sectional area results in part from an

Address for correspondence:

Dr. R. J. Maughan

Institute of Environmental and Offshire Medicine

Ashgrove Road West

ABERDEEN AB9 2ZD sectional area was observed; in both studies there was approximately a two-fold range in this ratio. In view of the magnitude of the training response which can be induced in skeletal muscle, it seems possible that at least some of this variability may be a result of differences in the level of activity undertaken by normal subjects. The study of Ikai and Fukunaga (1968) showed that the force per unit cross-sectional area of the elbow flexors was independent of age and sex; in a group of judo experts, who were presumably engaged in a significant amount of training of this muscle group, the strength and cross-sectional area of the muscle were both greater than in untrained subjects, with the result that these groups did not differ in the strength:cross-sectional area 
ratio. In contrast to this result, the same authors later reported that a strength training programme lasting 100 days was able to produce a $92 \%$ increase in strength accompanied by a $23 \%$ increase in muscle cross-sectional area (Ikai and Fukunaga, 1970). Clearly, therefore, there has been a large increase in the strength per unit crosssectional area.

The strength and size of skeletal muscle can both be increased by subjecting the muscle to a suitable training regimen. Experience suggests that muscle strength and muscle size can be selectively altered, as in the case of the competitive weightlifter who seeks to increase the maximum force which can be developed without a corresponding gain in body mass. In contrast to this, the bodybuilder aims to increase the dimensions of the muscle, but is not concerned with functional improvements in terms of strength. Using computed tomography scanning to measure muscle cross-sectional area, Haggmark et al (1978) found that the thigh muscle cross-sectional area of elite weightlifters could be up to twice that of relatively untrained subjects. No measurements of muscle strength were made in that study, but it is well established that weightlifters are capable of producing greater isometric force than untrained individuals (Tomvall, 1963).

In the studies of Ikai and Fukunaga $(1968,1970)$ an ultrasonic technique was used to obtain estimates of the area occupied by the elbow flexor muscles. With the development of computerised tomography as a means of obtaining cross-sectional images of the body, greater accuracy in the measurement of muscle crosssectional area is possible (Ferrucci, 1979). The aim of the present study was to use this technique to assess the cross-sectional area of the knee extensor muscles in strength-trained and untrained subjects and to relate these measurements to the maximum isometric force which could be produced.

\section{METHODS}

\section{Subjects}

The subjects participating in this study consisted of an untrained control group and a strength-trained group. All subjects were male. The control group consisted of 35 volunteers, none of whom, at time of study, was engaged in any specific training programme, although most participated in occasional recreational activities. None of these subjects had any known neurological or muscular disorders.

The trained group consisted of 8 individuals who had been engaged in a strenuous weight-training programme for a period of at least two years (range 2-12 years). All trained at least three times per week, although none participated in competitive weight-lifting events. In addition to the standard measurements of height and weights, the percentage body fat of each subject was assessed from measurement of skinfold thicknesses by the procedure described by Durnin and Ramahan (1967).

\section{TABLE I}

Physical characteristics of the untrained $(n=35)$ and trained $(n=8)$ subjects. Lean body mass was calculated as the fat-free body mass. Body fat content was estimated from skin-fold thicknesses (Durnin and Rahaman, 1967).

\begin{tabular}{lccccc} 
& \multicolumn{2}{c}{ Untrained } & \multicolumn{2}{c}{ Trained } \\
& Mean & SD & & Mean & SD \\
Age $(\mathrm{yrs})$ & 28 & 6 & & 26 & 4 \\
Height $(\mathrm{cm})$ & 175 & 6 & & 176 & 9 \\
Weight $(\mathrm{kg})$ & 72.0 & 10.2 & $*$ & 81.3 & 10.3 \\
Body fat $(\%)$ & 16.2 & 5.1 & & 13.9 & 2.9 \\
Lean body mass $(\mathrm{kg})$ & 59.7 & $7.2 \quad * * *$ & 69.9 & 9.0
\end{tabular}

\section{Measurement of muscle strength}

The muscle group studied in this investigation was the knee-extensor group, located in the anterior aspect of the thigh; this group consists of $m$ rectus femoris, $m$ vastus lateralis, $m$ vastus intermedius and $m$ vastus medialis. For the purposes of this study, strength wase defined as the maximum voluntary isometric force which could be produced by the muscle. The force produced was measured via a broad strap placed around the lower leg, immediately proximal to the malleoli. The force of contraction of the muscle was not, therefore, measured directly, but has been estimated as the torque produced by the muscle acting across the knee joint. For all measurements, the knee joint was held at an angle of $90^{\circ}$ and the subject was restrained in the apparatus with the hip joint also flexed at $90^{\circ}$. This apparatus has previously been described in detail (Maughan et al, 1983).

The newton $(N)$, the preferred intemational unit of force, is defined as the force that imparts an acceleration of one metre per sec. per sec. on a mass of one $\mathrm{kg}$ (i.e. $1 \mathrm{~N}=1 \mathrm{~kg} \cdot \mathrm{m} \mathrm{x} \mathrm{s}^{-2}$ ).

Muscle strength was measured separately on each leg for all subjects; only the stronger leg in each case has been considered in the discussion of the results. All subjects were given at least three attempts to produce a maximum contraction with each leg. Where significant differences between the two best efforts existed after three contractions, further attempts were allowed. The precautions outlined by Edwards et al (1977) to ensure a maximal effort were followed in all cases. 


\section{Measurement of muscle cross-sectional area}

The procedures used to measure the muscle crosssectional area have been described in a previous report (Maughan et al, 1983). All measurements were made by computed tomography, using an Elscint Exel CGT 905 CT scanner. The mid-thigh level, at which all measurements were made, was taken to be the midpoint between the greater trochanter and the upper border of the patella; each leg was scanned separately to ensure optimal resolution. Because of the geometry of the scanner, it was not possible for subjects to adopt the same position as that in which the measurements of muscle strength were made: subjects assumed a supine position, whereby the knee joint was at an angle of $135^{\circ}$, and the hip joint at an angle of $45^{\circ}$. This position was constant for all subjects.

From the image produced by the scanner, the crosssectional area occupied by the knee-extensor muscles was measured by a computer-based planimetric system. All measurements were made by the same operator.

\section{Statistical analysis}

Comparisons between the two groups of subjects were assessed for statistical significance by means of Student's t-test for unpaired data. In the control group of subjects, linear regression analysis was performed by the least squares method.

\section{Ethical considerations}

Prior approval for this study was granted by the Joint Ethical Committee of Aberdeen University and Grampian Health Board. The potential hazards attached to participation in the investigation were fully explained to all subjects and their written consent to participate was obtained. Computed tomography is an X-ray scanning technique and therefore involves exposure of the subject to a certain amount of ionising radiation, although the dose involved is relatively small (Perry and Bridges, 1973). The scanning protocol used in this study resulted in a radiation dose of $9 \mathrm{mSv}$ per scan, giving a total exposure for both legs of $18 \mathrm{mSv}$. The recommended maximum exposure for human volunteers is $\mathbf{5 0} \mathrm{mSv}$ per annum (National Radiological Protection Board, 1983).

\section{RESULTS}

There was no significant difference between the untrained and trained groups in terms of age, height or body fat content (Table I). The trained subjects, however, were heavier $(p<0.05)$ and had a greater lean body mass ( $<<0.001$ ) than the untrained subjects. In 26 of the 35 untrained subjects and 5 of the 8 trained subjects, the right leg was stronger than the left leg. A comparison between legs for each subject is shown in Fig 1a. Differences between legs were generally rather small, with four exceptions. One trained subject had a

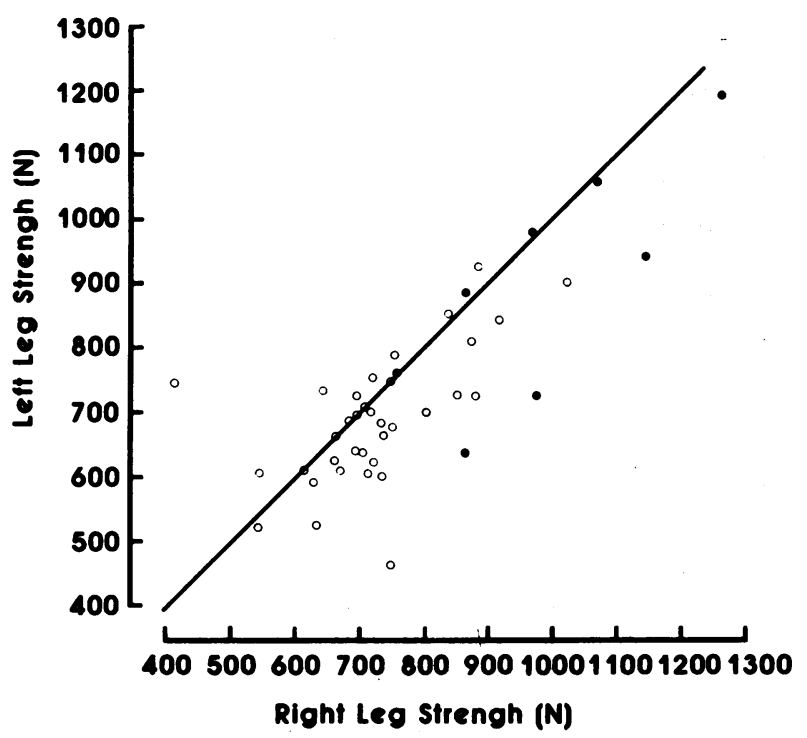

Fig. 1a: A comparison between the maximum voluntary isometric force which could be produced by right and $\frac{}{\mathbb{D}}$ left legs of each subject. The line of identity is indicated $\exists$ by the solid line. Untrained subjects are indicated by open circles $(\mathrm{O})$ and trained subjects by closed circles $\overrightarrow{\overrightarrow{0}}$ (०).

history of hamstring injury in one leg; quadrice strength and cross-sectional area were both markedFy less (by $26 \%$ and $11 \%$ respectively) in the injured leg as compared with the contralateral limb. In another of the trained subjects, a knee injury prevented the application $\Phi$ of full force with the left leg. One of the untrained $\overrightarrow{\vec{B}}$ subjects had undergone unilateral knee surgery approxi- $\frac{0}{3}$ mately 5 years previously: the knee extensor muscles of $\vec{J}$ the operated leg were weaker by $42 \%$ and smaller by $21 \%$ than those of the contralateral leg. Another of the untrained subjects had a left leg which was weaker by $38 \%$ and smaller by $15 \%$ than the right leg; nothing in 3 this subject's history could account for this discrepancy. The mean percentage difference in strength between the stronger and weaker legs was $9.4 \pm 9.5 \%$ (mean \pm SD; range $=0.0-42.3$ ) in the untrained group and $10.0 \pm$ $11.3 \%(0.3-26.1)$ in the trained group. Variations in $\frac{0}{5}$ muscle cross-sectional area between the two legs of any $\frac{D}{O}$ subject also tended to be small, with the exception of the 4 cases described above (Fig. 1b). The differences in $\tilde{N}$ cross-sectional area between the weaker and stronger legs were $-2.8 \pm 5.7 \%(-20.7$ to +8.0$)$ in the untrained 0 group and $-4.8 \pm 5.6 \%(-12.3$ to +0.3$)$ in the trained $\omega$ group. In all subsequent discussion of the results, data? obtained from the stronger leg of each subject only are considered.

The mean maximum voluntary isometric force which could be produced by the untrained subjects was $742 \pm \frac{\mathrm{D}}{\mathrm{D}}$ $100 \mathrm{~N}$ (range $543-1024$ ). Not surprisingly, the trained $\frac{\pi}{\square}$ 


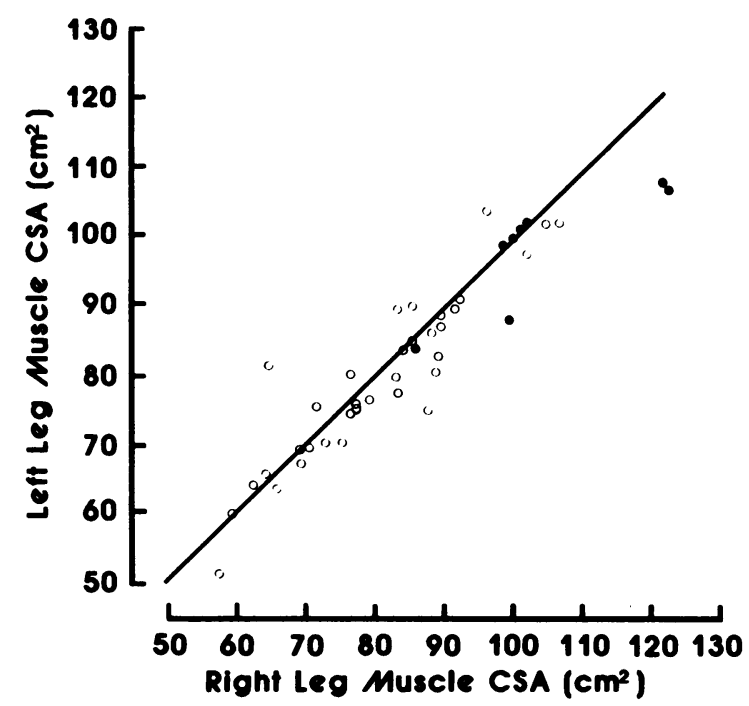

Fig. 1b: Comparison between cross-sectional area of the knee-extensor muscles in the right and left legs of untrained (O) and trained ( $(\bullet)$ subjects. The line of identity is shown by the solid line.

subjects were stronger ( $p<0.001$ ) than the untrained subjects, the mean strength being $992 \pm 162 \mathrm{~N}$ (range $799-1261 \mathrm{~N}$ ). The strength of the untrained subjects was not significantly correlated $(r=0.32, p>0.05)$ with body weight (Fig. 2). The ratio of strength to body weight was lower $(p<0.001)$ in the untrained group than in the trained group (Table II). A significant $(r=0.45, p<0.01)$ relationship was observed to exist between strength and lean body mass in the untrained subjects (Fig. 3); again, the ratio of strength and lean body mass was lower $(p<0.05)$ in the untrained than in the trained subjects (Table II).

\section{TABLE II}

Muscle strength measurements in untrained and trained subjects. Strength has been related to body weight (BW) and lean body mass (LBM). Also included are values for muscle cross-sectional area (CSA) and the strength/ cross-sectional area ratio.

\begin{tabular}{lccccc} 
& \multicolumn{2}{c}{ Untrained } & & \multicolumn{2}{c}{ Trained } \\
Strength (N) & 742 & 100 & $* *$ & 992 & 162 \\
Strength (N/kgBW) & 10.45 & 1.75 & $* *$ & 12.36 & 2.30 \\
Strength (N/kgLBM) & 12.53 & 1.72 & $*$ & 14.35 & 2.58 \\
Muscle CSA (cm $\left.{ }^{2}\right)$ & 81.6 & 11.8 & $* *$ & 104.1 & 12.3 \\
Strength/CSA ratio & 9.20 & 1.29 & NS & 9.53 & 1.01 \\
$\quad$ * $p<0.05$ & $* * p<0.01$ & $* * * p<0.001$
\end{tabular}

The mean cross-sectional area of the knee extensor muscles in these two populations of subjects was 81.6 $\pm 11.8 \mathrm{~cm}^{2}$ in the untrained group and $104.1 \pm 12.3$

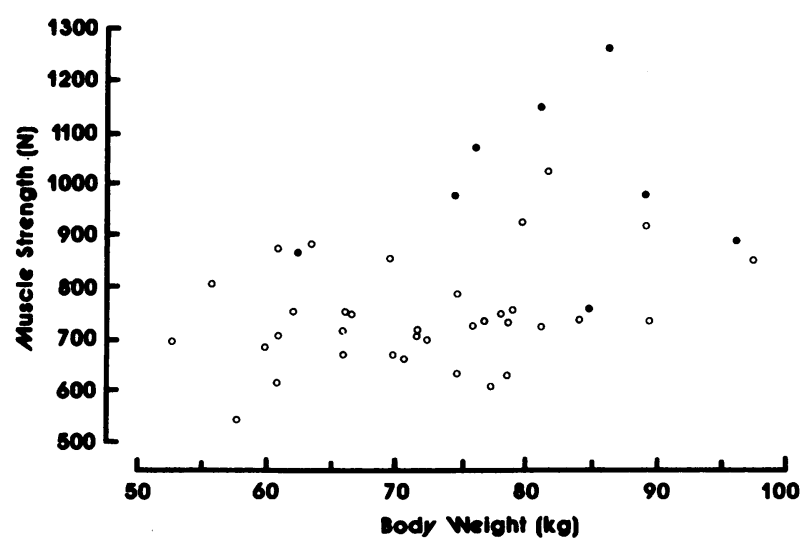

Fig. 2: The relationship between muscle strength and body weight. No significant correlation was observed to exist between these variables in the untrained subjects. The trained subjects had a higher $(p<0.01)$ strength per unit body weight (12.35 \pm 2.30$)$ than the untrained subjects (10.45 \pm 1.75$)$. Symbols used are as in Fig. 1 .

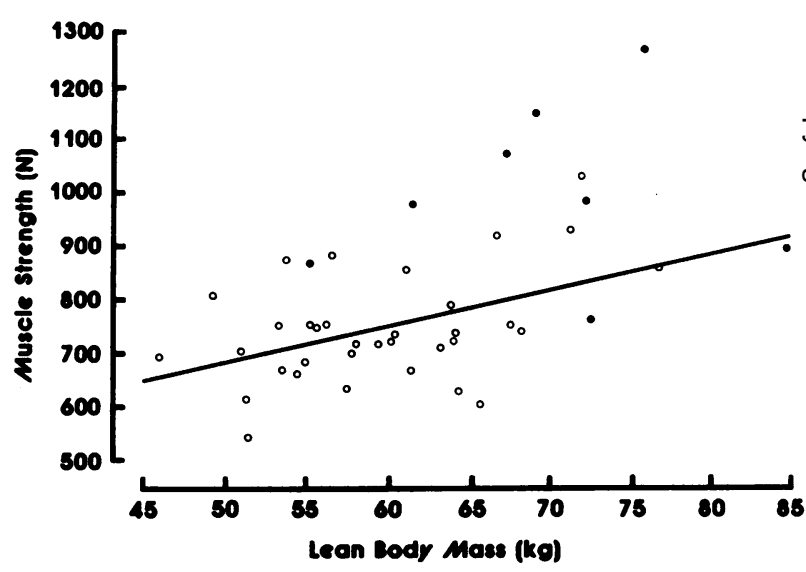

Fig. 3: A significant relationship was observed to exist between muscle strength and lean body mass in the untrained subjects $(r=0.45, p<0.01)$. The trained subjects had a significantly higher $(p<0.05)$ ratio of strength to lean body mass than did the untrained subjects. Mean ratios were 14.35 \pm 2.58 and $12.53 \pm$ 1.72 for the trained and untrained groups respectively. Symbols used are as in Fig. 1.

$\mathrm{cm}^{2}$ in the trained subjects. The strength-trained subjects had a significantly greater $(p<0.001)$ muscle cross-sectional area than the untrained subjects. In both groups of subjects, the weaker leg had a significantly smaller muscle cross-sectional area than the stronger leg. In the untrained group, the cross-sectional area of the weaker leg was $79.5 \pm 12.4 \mathrm{~cm}^{2}$, in the trained group, 
the cross-sectional area of the weaker leg was $98.7 \pm$ $4 \mathrm{~cm}^{2}$.

In the untrained subjects, strength was significantly correlated with muscle cross-sectional area $(r=0.56$, $p<0.001)$. This relationship is presented graphically in Fig. 4. The mean ratio of strength to cross-sectional area in this group of subjects was $9.20 \pm 1.29$ (range 7.07 - 12.55); this was not significantly different from the ratio which was found to exist in the trained group (9.53 \pm 1.01 ; range 7.57 - 10.81).

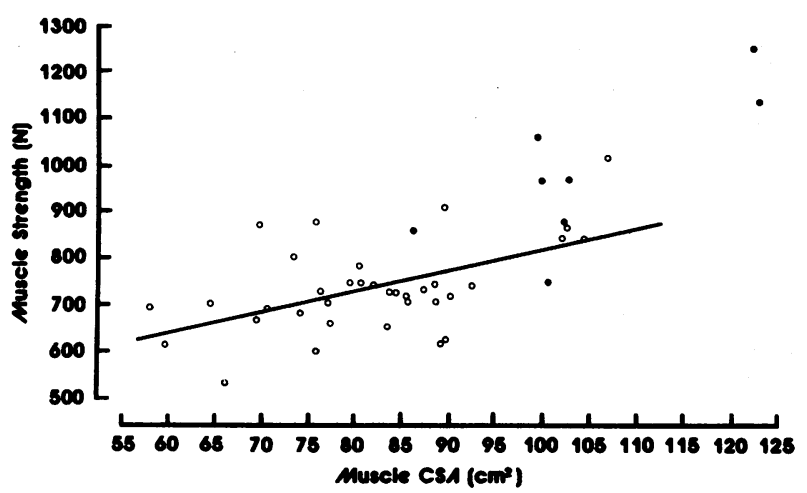

Fig. 4: Muscle strength was significant/y $1 r=0.56$, $p<0.001)$ correlated with muscle cross-sectional area in the untrained subjects. The mean ratio of strength to cross-sectional area was not significantly different between the untrained $(9.20 \pm 1.29)$ and trained $(9.53$ $\pm 1.01)$ groups of subjects. Symbols used are as in Fig. 1.

This result suggests that the greater strength of the trained subjects can be accounted for entirely by an adaptive hypertrophy of the muscle. However, in the untrained subjects, a significant inverse relationship $(r=-0.55, p<0.001)$ was observed to exist between the strength/cross-sectional area ratio and the muscle cross-sectional area (Fig. 5). The greater the muscle crosssectional area, the lower the strength/cross-sectional area ratio. It is apparent from this relationship that the strength/cross-sectional area ratio of the trained group was appreciably higher than would be predicted for a normal population having such a large muscle crosssectional area. In the untrained group, a muscle crosssectional area of $104.1 \mathrm{~cm}^{2}$, the mean value obtained from the weight-trained group, would be expected to be associated with a muscle strength of $848 \mathrm{~N}$ and a muscle strength/cross-sectional area ratio of 7.85 , compared with the observed results for this group of $992 \mathrm{~N}$ and 9.53 respectively. This suggests that the training programme undertaken by the strength-trained subjects has resulted in an increased muscle cross-sectional area without the decrease in the strength/cross-sectional area ratio which might be expected to accompany such a degree of hypertrophy.

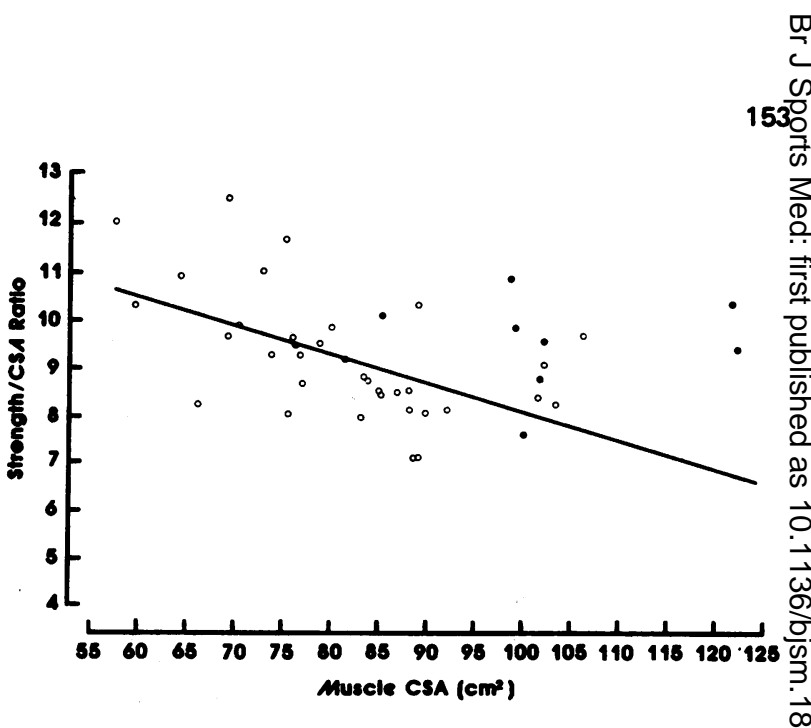

Fig. 5: An inverse relationship existed between the muscle strength: cross-sectional area ratio and muscles cross-sectional area. This relationship was statisticallyo significant $(r=0.55, p<0.001)$.

\section{DISCUSSION}

In the untrained group of subjects the major deter $\stackrel{\mathbb{D}}{-}$ minant of muscle strength appears to be the muscled cross-sectional area, as previously reported (Ikai and Fukunaga, 1968; Maughan et al, 1983). This is evideinto from the significant $(p<0.001)$ correlation which exists ${ }^{A}$ between muscle strength and muscle cross-sectional arê?.0 The trained subjects appear to conform to this pattein their muscles are larger (by a mean of 34\%) and capable of exerting greater force (by a mean of 28\%) than areo those of the untrained subjects. The mean value of the ratio of strength to cross-sectional area is therefore not significantly different between the two groups. Froms this it would appear that the effect of the training pro-gramme which these individuals had undertaken was to increase the size of the muscles, and that the increased capacity to develop force was consequent upon thisen hypertrophy.

Previous studies in which subjects have been studieoth before and after strength-training of muscle have suggested that increases in strength are greater than those which would be predicted from the increase in? cross-sectional area alone. Ikai and Fukunaga (1970) reported that a period of strength-training produced a greater increase in the maximum voluntary force which $N_{5}$ could be produced than in muscle cross-sectional area. Young et al (1983) have also reported greater increases in isometricstrength (15\%) than in muscle cross-sectional $\omega$ area (6\%) in response to a dynamic exercise programme consisting of three sessions per week and of 5 weeks? duration. In contrast, Dons et al (1979) found noes changes in isometric strength in response to 7 weeks of dynamic muscle training, also carried out 3 times pero week; they did, however, observe significant increasesd in dynamic strength in response to the training regimen 
which involved repeated contractions at $80 \%$ of dynamic muscle strength. Strangely, isometric muscle strength increased significantly in their control group. Muscle cross-sectional area increased to a similar extent in the trained and control groups. Their ultrasound technique for measuring thigh muscle cross-sectional area did not, however, allow them to distinguish between muscle and subcutaneous fat. Changes in muscle cross-sectional area may therefore have been masked by alterations in the thickness of the subcutaneous tissue layer.

The training programme undertaken by subjects who volunteer for studies such as those described above are of necessity of much shorter duration, and usually of much lower intensity, than those undertaken by the trained subjects in the present study. The results obtained from these longitudinal studies do, however, suggest that factors other than local muscle hypertrophy can contribute significantly to the gains in muscle strength resulting from such programmes. Ikai (1973) proposed that part of the training effect, particularly in the early stages of a training regimen, is due to neural factors. In particular he identified an increased central drive to the muscle as being a major contributory factor.

This concept was supported by the observation of Ikai et al (1967) that the maximum force produced by the thumb adductor muscle in response to electrical stimulation was $30 \%$ greater than that which could be produced by voluntary effort. A similar enhancement of muscle strength was also found by the same group of investigators to be produced by hypnotic suggestion (Ikai and Steinhaus, 1961). Sale et al (1983) have recently suggested that a period of muscle training by weight lifting can result in an increased motor neurone discharge during maximum voluntary effort in the trained state, and that this mechanism is at least partly responsible for the gain in muscle strength resulting from training. They also proposed that in improved synchronisation of notor unit activation could contribute to increased force production by the muscle. This latter mechanism was originally suggested by Milner-Brown et al (1975), who found a greater degree of synchronisation of motor unit activation in muscles of weightlifters and manual workers than in inactive individuals; six weeks of isometric muscle training in previously inactive subjects was also found to increase the degree of synchronisation observed.

These results indicate that the maximum force which a muscle is capable of producing cannot be exerted by volitional effort in untrained subjects. If this is the case, the suggestion of Ikai (1973) that strength training can effectively increase the fraction of maximum muscular strength which can be recruited by voluntary effort would appear to be reasonable. In direct contradiction to this, however, is the report by Merton (1954) that no difference exists between the maximum voluntary force which can be produced by the adductor pollicis muscle and the maximum force which results from an electrically induced tetanus. Belanger and McComas (1981) also found that force production during electrical stimulation of human muscle (dorsiflexor and plantar-flexor muscles of the ankle) was comparable with that produced by voluntary effort. Electrical stimulation of part of the knee extensor group has been used extensively, but full activation of this muscle group is extremely uncomfortable, and involves significant risk of patellar displacement. Edwards et al (1975) have reported the results of activation of the entire knee extensor muscle group by electrical stimulation of the femoral nerve, although this procedure was carried out in only one subject; the force produced by tetanic stimulation was the same as that produced by a maximum voluntary effort. If this is the case, psychological factors would appear to be of little or no consequence for the expression of musclar strength.

The strength/cross-sectional area ratio of the trained group is not different from that of the untrained group in the present study. Consideration must, however, be given to the relationship which exists between this ratio and the muscle cross-sectional area in the untrained subjects (Fig. 5). Although strength increases with increasing muscle cross-sectional area, the ratio of strength to cross-sectional area shows a tendency to decrease as the cross-sectional area increases. This effect? is a consequence of the internal architecture of the four muscles which comprise the knee-extensor musculature. $M$ rectus femoris has a bipennate structure, whereas the three vasti muscles are pennate (Williams and Warwick, 1980). This being the case, forces developed in the individual fibres which comprise these muscles act at an angle to the long axis of the muscle. From Fig. 6 it is apparent that the component of the force which acts along the length of the muscle is equal to the cosine of the angle of pennation. Strap-like muscles, where the individual muscle fibres run the complete length of the muscle parallel to its long axis, are thus best suited for force generation. The greater the angle of pennation, the smaller the force produced in the tendon in response to a given level of force production by the individual muscle fibres. It has been reported (Alexander and Vermon, 1975), on the basis of results obtained from a single cadaver, that the angle of pennation of each of the muscles comprising the knee extensor group is approximately $13-18^{\circ}$. Wickiewiez et al (1983) dissected limbs obtained from three human cadavers: the angle of pennation of each of the four muscles in each specimen was reported to be approximately $5^{\circ}$. They did report considerable differences between the proximal and distal portions of vastus medialis and vastus lateralis, with pennation angles as great as $45^{\circ}$ in the distal region of these muscles. The technical problems involved in any attempt to measure this angle in the intact individual would appear to be insurmountable. From a study of a 
number of post-mortem specimens, Haxton (1944) concluded that the angle of pennation varied little between individuals in the two muscles studied, the soleus and the gastrocnemius.

Increases in the cross-sectional area of a muscle can conceivably occur from increases in the total number of fibres in the muscle, the area of each fibre remaining approximately constant, or by enlargement of some or all of the individual muscle fibres. Recently, it has been suggested that the total number of fibres in a muscle is fairly constant, even in individuals with large differences in muscle cross-sectional area (Schantz et al, 1981). This has been disputed by MacDougall et al (1982) and Tesch and Larsson (1982), who found that elite body builders, who displayed marked muscular hypertrophy, had normal muscle fibre diameters, leading to the conclusion that they possessed a greater number of muscle fibres than "normal" subjects; this effect could be due to genetic factors or to hyperplasia resulting from longitudinal fibre splitting. Support for both the individual fibre hypertrophy theory (Gollnick et al, 1981) and the hyperplasia theory (Gonyea et al, 1977; Gonyea, 1980) has come from experimental studies on animal muscle.

Irrespective of the mechanism by which traininginduced muscle hypertrophy occurs, considerations of space dictate that this effect must be associated with an increased angle of pennation (Gollnick et al, 1981). In the hypertrophied muscle, therefore, a smaller fraction of the force generated by the muscle fibres acts along the axis of the muscle (Fig. 6). This explains the observation that the force per unit cross-sectional data decreases as the cross-sectional area increases (Fig. 5). If this effect were to apply to the strength-trained subjects in this study, however, it would be expected that the mean strength per unit cross-sectional area would be less than that of the untrained group, due to their greater muscle area. This is clearly not the case.

In some way, therefore, the weight-trained subjects have been able to compensate for the decrease in the strength/cross-sectional area ratio which would normally be expected to accompany their muscle hypertrophy. There would appear to be two mechanisms by which this effect might be produced. The first of these is an increased neural drive. As previously discussed, it seems likely from the results of Ikai and Steinhaus (1961) and Ikai and Fukunaga (1970) that this is the case. There is a considerable amount of evidence, however, which indicates that neural factors are probably of little importance (Merton, 1954; Edwards et al, 1975; Belanger and McComas, 1981).

The second mechanism which can be postulated involves an increased density of contractile protein in

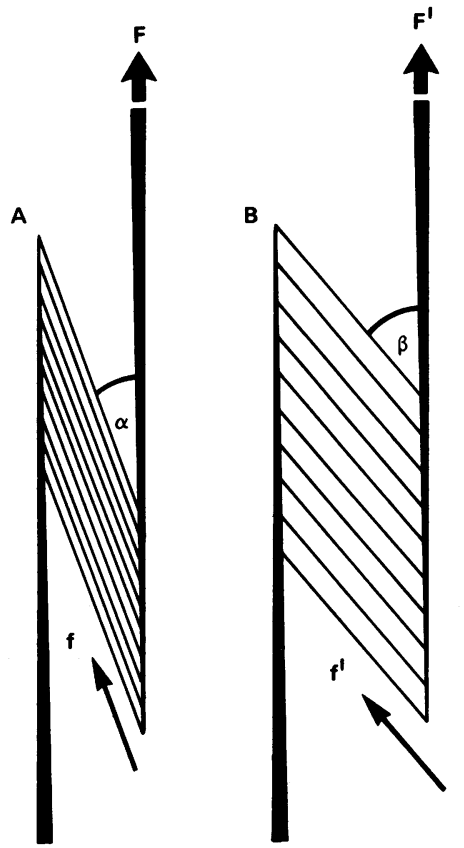

Fig. 6: Diagrammatic representation of the effects of muscular hypertrophy on the angle of pennation of the fibres in a uni-pennate skeletal muscle.

a) Untrained muscle. The force (F) acting along the lonf. axis of the muscle is a function of the force $(f)$ produced by the individual fibres and of the angle of pennation (a).

b) Trained muscle. An increase in the diameter of the individual muscle fibres results in an increase in the angle of pennation and in an increase in muscle crosssectional area. If the force produced by individual fibres $\left(f^{\prime}\right)$ remains the same as $(f)$, then the force $\left(F^{\prime}\right)$ acting along the long axis of the muscle will be less than $(F)$, since $\beta$ is greater than $a$.

the muscle of the trained subjects, enabling an increased force to be generated within the muscle fibre. This suggestion, however, is not supported by the experimental data of MacDougall et al $(1979 ; 1982)$, who found a lower density of contractile protein in the muscles of body builders than in control subjects, and also observed a reduction in the amount of myofibrillar protein per unit volume in response to a training programme.

\section{ACKNOWLEDGEMENTS}

R. J. Maughan is supported by a grant from Offshore Medical Support Limited, Aberdeen. 


\section{REFERENCES}

Alexander, R. MCN. and Vernon, A., 1975 "The dimensions of knee and ankle muscles and the forces they exert". J.Hum.Mov.Stud. 1: 115-123.

Belanger, A. Y. and McComas, A. J., 1981 "Extent of motor unit activation during effort". J.Appl.Physiol. 51: 1131-1135.

Dons, B., Bollerup, K., Bonde-Petersen, F. and Hancke, S., 1979 "The effect of weight-lifting exercise related to muscle fibre composition and muscle cross-sectional area in humans". Eur.J.Appl.Physiol. 40: 95-106.

Durnin, J. V. G. A. and Rahaman, M. M., 1967 "The assessment of the amount of fat in the human body from measurements of skinfold thickness". Br.J.Nutr. 21: 681-689.

Edwards, R. H. T., Hill, D. K. and Jones, D. A., 1975 "Heat production and chemical changes during isometric contractions of the human quadriceps muscle". J.Physiol. 251: 303-315.

Edwards, R. H. T., Young, A., Hosking, C. D. and Jones, D. A., 1977 “Human skeletal muscle function: description of tests and normal values". Clin.Sci.Mol.Med. 52: 283-290.

Ferrucci, J. T., 1979 “Body ultrasonography”. New Engl.J.Med. 300: 590-602.

Gollnick, P. D., Timson, B. F., Moore, R. L. and Riedy, M., 1981 "Muscular enlargement and number of fibres in skeletal muscles of rats". J.Appl.Physiol. 50: 936-943.

Gonyea, W., 1980 "Role of exercise in inducing increases in skeletal muscle fibre number". J.Appl.Physiol. 48: 421-426.

Gonyea, W., Erickson, G. C. and Bonde-Petersen, F., 1977 “Skeletal muscle fibre splitting induced by weight-lifting్ exercise in cats". Acta Physiol.Scand. 99: 105-109.

Haggmark, T., Jansson, E. and Svane, B., 1978 “Cross-sectional area of the thigh muscle in man measured by computed tomography". Scand.J.Clin.Lab.Invest. 38: 355-360.

Haxton, H. A., 1944 "Absolute muscle force in the ankle flexors in man". J.Physiol. 103: 267-273.

Ikai, M., 1973 "Training of muscle strength and power in athletes". Br.J.Sports Med. 7: 43-47.

Ikai, M. and Fukunaga, T., 1968 "Calculation of muscle strength per unit cross-sectional area of human muscle by means of ultrasonic measurement". Int.Z.angew.Physiol. 26: 26-32.

Ikai, M. and Fukunaga, T., 1970 "A study on training effect on strength per unit cross-sectional area of muscle by means of ultrasonic measurement". Int.Z.angew.Physiol. 28: 173-180.

Ikai, M. and Steinhaus, A. H., 1961 "Some factors modifying the expression of human strength". J.Appl.Physiol. 16: 157-163.

Ikai, M., Yabe, K. and Ischii, K., 1967 "Muskelkraft und musculare Ermundung bei willkurlicher Anpassung und elektrischer Reizung der Muskels". Sportarzt und Sportmedizin 5: 197-204.

MacDougall, J. D., Sale, D. G., Moroz, J. R., Elder, C. G. B., Sutton, J. R. and Howald, H., 1979 "Mitochondrial volume density in human skeletal muscle following heavy resistance training". Med.Sci.Sports 11: 164-167.

MacDougall, J. D., Sale, D. G., Elder, C. G. B. and Sutton, J. R., 1982 “Muscle ultrastructural characteristics of elite powerlifters and bodybuilders". Eur.J.Appl.Physiol. 48: 117-126.

Maughan, R. J., Watson, J. S. and Weir, J., 1983 "Strength and cross-sectional area of human skeletal muscle". J.Physiol. 338: 37-49. 
Merton, P. A., 1954 "Voluntary strength and fatigue". J.Physiol. 123: 553-564.

Milner-Brown, H. S., Stein, R. B. and Lee, R. G., 1975 "Synchronisation of human motor units: possible roles of exercise and supraspinal reflexes". Electroencephalog.Clin. Neurophysiol. 38: 245-254.

National Radiological Protection Board, 1983 “Draft guidance notes for the protection of persons against ionising radiation arising from medical and dental use". HMSO, London.

Perry, B. J. and Bridges, C., 1973 “Computerised transverse axial scanning (tomography): Part 3. Radiation dose considerations". Br.J.Radiol. 46: 1048-1051.

Sale, D. B., MacDougall, J. D., Upton, A. R. M. and McComas, A. J., 1983 “Effect of strength training upon motoneuron excitability in man". Med.Sci.Sports Ex. 15: 57-62.

Schantz, P., Randall Fox, E., Norgren, P. and Tyden, A., 1981 "The relationship between the mean muscle fibre area and the muscle cross-sectional area of the thigh in subjects with large differences in thigh girth". Acta Physiol.Scand. 113: 537-539.

Tesch, P. and Larsson, L., 1982 “Muscle hypertrophy in body builders". Eur.J.Appl.Physiol. 49: 301-306.

Tornvall, G., 1963 "Assessment of physical capabilities with special reference to the evaluation of maximal voluntary isometric muscle strength and maximal working capacity". Acta Physiol.Scand. 58: Suppl. 201.

Wickiewiez, T. L., Roy, R. R., Powell, P. L. and Edgerton, V. R., 1983 "Muscle architecture of the human lower limb". Clinical Orthopaedics and Related Research 179: 275-283.

Williams, P. L. and Warwick, R., 1980. Gray's Anatomy. 36th Edition. London, Churchill.

Young, A., Stokes, M., Round, J. M. and Edwards, R. H. T., 1983 "The effect of high-resistance training on the strength and cross-sectional area of the human quadriceps". Eur.J.Clin. Invest. 13: 411-417.

\section{BOOK REVIEW}

Title:

MUSCLE FUNCTION TESTING

Author: $\quad$ Vladimir Janda

Publisher: $\quad$ Butterworths: London, 1983

Price: $£ 35$ Hard cover

The book, which was first published in the Czech language in 1979, is designed as a practical manual for use by physiotherapists. It consists of 260 pages and is very well presented in terms of both text and illustrations. The main part of the book is concerned with a detailed description of muscle function tests for muscles responsible for movement in the face, trunk, upper limb and lower limb. At the start of each subsection, the relevant joint movements, muscles and nerve supply are described. Tests of muscle function are described in relation to specific joint movements; photographs are used to help show the position of the subject during each test and the application of resistance by the therapist. In each test, muscle function is assessed with regard to a six point scale, which ranges between normal function and complete paralysis. In addition to muscle function testing there are also sections on identifying shortened muscles and hypermobile joints. In general, the book would seem to be of considerable benefit to physiotherapists, but is too specific to be of particular interest to the majority of physical education teachers and sports coaches. 